\title{
Racializing Gender: Public Opinion at the Intersection
}

\section{Erin C. Cassese}

\section{West Virginia University}

\author{
Tiffany D. Barnes
}

\section{University of Kentucky}

Regina P. Branton

\section{University of North Texas}

H fforts to understand the political implications of categorical prejudices nature of social groups. Evaluating attitudes toward members of a single social category (e.g., African-Americans) in isolation can produce misleading conclusions, as racial cues commonly coincide with gender cues and create meaningful subgroups (McConnaughy and White 2014). The idea that different subgroups of women experience distinctive forms of discrimination is reflected in the concept of "double jeopardy." Double jeopardy suggests that black and Hispanic women experience discrimination differently from white women or men

The authors would like to thank Angela Bos, Mirya Holman, Corrine McConnaughy, Heather Ondercin, Mark Peffley, Monica C. Schneider, Dara Strolovitch, Steve Voss, Bas Von Doorn, the Quantitative Institute for Policy and Social Research at the University of Kentucky, and the participants of the 2013 Visions in Methodology (VIM) meeting.

Published by Cambridge University Press 1743-923X/15 \$30.00 for The Women and Politics Research Section of the American Political Science Association.

(C) The Women and Politics Research Section of the American Political Science Association, 2015 doi:10.1017/S1743923X14000567 
of color because they simultaneously belong to a low-status gender group and a low-status racial/ethnic group (King 1988; Levin et al. 2002; cf. Sidanius and Veniegas 2000). As a result, women who are racial or ethnic minorities face a cumulative discrimination that extends beyond racism or sexism alone (King 1988; Purdie-Vaughns and Eibach 2008). ${ }^{1}$

The double jeopardy concept, and research on intersectionality more broadly, ${ }^{2}$ suggests that attitudes toward race and gender interact in politically consequential ways. In addition, literature on system justification and social dominance orientation demonstrate that attitudes toward gender and race meaningfully covary because they are both "legitimizing ideologies," which stem from a common underlying psychological orientation toward structural inequality (Jost et al. 2003; Jost, Federico, and Napier 2009; Sidanius and Pratto 1993). ${ }^{3}$ Legitimizing ideologies are beliefs about the origins of socioeconomic inequality among social groups that facilitate tolerance for inequality in the current system and preferences for the status quo. Racial resentment and modern sexism are examples of these kinds of beliefs. Both perspectives deny that inequality experienced by African-Americans and women, respectively, stems from systematic discrimination. Instead inequality is attributed to stereotypical characteristics of groups (e.g., blacks as lazy, women as passive and/or maternal). Because discrimination is not understood to be the source of the problem, these groups are considered undeserving of special forms of government assistance.

In spite of this commonality between racial resentment and modern sexism, public attitudes toward race and gender have been explored relatively independently of one another in mainstream political science research. A lack of integrated work leaves many important questions unanswered: Do race and gender attitudes operate relatively

1. Cumulative discrimination refers to the idea that people can experience multiple forms of discrimination simultaneously. These forms of discrimination are not working independently of one another but instead relate to each other in an interactive or cumulative fashion. The precise nature of the relationship among various forms of discrimination is the subject of ongoing debate (see pp. 9 and $22-23$ in this article).

2. As we explain in the next section, intersectionality refers to "analytic approaches that simultaneously consider the meaning and consequences of multiple categories of identity, difference, and disadvantage" (Cole 2009, 170). It is essentially the recognition that all people belong to multiple groups and that group memberships intersect in ways that meaningfully effect their interests, identities, and daily lives.

3. Structural inequality refers to socioeconomic stratification based on group membership. Structural perspectives attribute group-based inequality to systemic factors, such as the rules and practices of organizations and institutions that create different opportunity structures for different groups. 
independently, or do they work together to jointly shape policy attitudes? What does the relationship between them suggest about the "double jeopardy" facing black and Hispanic women in the United States? To answer these questions, we conducted an experiment in the Cooperative Congressional Election Study (CCES) that manipulated racial cues in a survey question about a policy to address wage discrimination facing women. By manipulating race in the context of a gender-related policy, we can better understand the process by which gender becomes "racialized" or the ways in which race and gender attitudes "collaborate" to shape policy support.

We find that support for fair-pay policy is enhanced when people perceive that women face systemic discrimination. At the same time, perceptions of racial discrimination also influence support for fair pay among a subset of white liberals and moderates when references to black or Hispanic women are added to the survey question. Among white liberals high in racial resentment, mentions of black and Hispanic racial cues activated racial prejudice and depressed policy support. White moderates high in racial resentment reacted similarly but only when black women (but not Hispanic women) were mentioned in the survey question. Among white conservatives, policy support is uniformly low across conditions, pointing more toward principled opposition to such policies regardless of how their beneficiaries are described. The significant role played by both modern sexism and racial resentment in shaping policy attitudes lends support to the concept of double jeopardy. But, the moderating effect of ideology suggests the intersectional biases held by white Americans are relatively complex and inherently politicized. This pattern of policy support is consistent with evidence of stratification among subgroups of women; many white Americans see white women as more deserving than black women and Latinas. This differential willingness to extend government assistance to groups of women based on their race or ethnicity points to the persistence of racial prejudice in white Americans' political attitudes and the continued challenges facing efforts to address race and gender-based economic stratification through effective public policy.

\section{INTERSECTIONS OF RACE AND GENDER}

Intersectionality is defined by its focus on the "simultaneous and interacting effects" of multiple social categories such as race, class, or 
gender (Simien and Hancock 2011, 185). Terms like "double jeopardy," "multiple jeopardy" (King 1988, 47), "triple oppression," and "discrimination-within-discrimination" (Kirkness 1988, 413) are often used to suggest that members of one marginalized group face additional discrimination based on their other essential characteristics. People at these intersections experience multiple "disempowering dynamics" that contribute to meaningful and politically consequential sources of difference within groups (Hancock 2007a, 2007b; Strolovitch 2007). When researchers attempt to study gender, for instance, while holding race and ethnicity constant, analysis tends to center exclusively on mean differences between men and women. Lumping all women together creates a false sense of unity and obscures the heterogeneity and associated inequalities present within women as a group (Cole and Stewart 2001; Huddy, Cassese, and Lizotte 2008).

Failure to look carefully into these intersections can render particularly disadvantaged subgroups of women invisible and impede effective policymaking. When race is "held constant" or overlooked, whiteness tends to emerge as an implicit default category, and, as a result, policy efforts tend to overemphasize the needs and experiences of middle-class white women (Crenshaw 1991, 1993; Hancock 2007b; Harris-Perry 2011; Strolovitch 2007). This invisibility of particular subgroups of women is a symptom of their multiple disadvantages. For instance, wage discrimination based on gender is often reported as a single figure - for example, women earn 77-78 cents on the dollar compared to men. Decomposed by race and ethnicity, however, the gap for African American women is estimated to be between about 62-66 cents on the dollar and between about 52-55 cents on the dollar for Latinas compared to white men (IWPR 2013). ${ }^{4}$ Thus, the presentation of a single wage gap obscures both the magnitude of the wage differential and the origins of the problem - casting it as a function of gender discrimination only and ignoring the joint influence of racial discrimination. Exploring gender independently of race has the effect of looking past the ways that racism and sexism mutually reinforce one another to form an interlocking system of oppression (Collins 2000).

4. Estimates vary because the gap is calculated in a variety of different ways: based on annual earnings versus weekly earnings, women over 15 years of age versus women over 18 , excluding or including selfemployed workers, using wage and salary workers only versus a more inclusive group of women. For more information, see the Institute for Women's Policy Research report, "The Gender Wage Gap" (2013). 


\section{PUBLIC OPINION AT THE INTERSECTIONS}

The intersection between racial attitudes and gender attitudes is of particular concern for public opinion researchers, many of whom seek to understand how social and political forces interact to produce and reproduce systemic inequalities. McConnaughy and White's (2014) subgroup model demonstrates that white Americans do not apply opinions and stereotypes about race or gender in isolation but rely on a more nuanced set of opinions and stereotypes about subgroups created by the intersection of race and gender. They find that on some dimensions - like violence - black and white women are viewed relatively similarly, while black men stand out as especially violent (see also Sidanius and Veniegas 2000). On other dimensions, such as intelligence and ambition, perceptions of white women and black women diverge considerably, with white women viewed as more ambitious and intelligent than black women. Popular characterizations of black women as "welfare queens" and "crack mothers" in public discourse similarly illustrate how race and gender form distinctive - and, in many cases, maligned - subgroups (Roberts 1999; Simien 2007).

Attitudes about race often condition attitudes about gender because they stem from common origins. Research on system justification theory (Jost et al. 2003) and social dominance orientation (Sidanius and Pratto 1999) suggests a set of epistemic motives underlie various attitudes toward inequality. ${ }^{5}$ People with a high acceptance of inequality maintain constellations of beliefs and behaviors designed to justify prevailing inequalities between groups. These belief structures are commonly referred to as system justification motives (Jost and Banaji 1994) or legitimizing ideologies (Sidanius, Pratto, and Bobo 1994) and can include orientations such as racial resentment, modern sexism, and political conservatism (Jost, Federico, and Napier 2009). A common facet of legitimizing ideologies is the denial or heavy discounting of discrimination as an explanation for inequality, instead attributing it to group characteristics - such as laziness. By attributing the problem to the group itself rather than society at large, a group's disadvantaged status becomes a justification for inaction rather than a rationale for

5. These legitimizing ideologies stem from a defensive motivation to perceive the world in ways that satisfy needs and values, such as the need for order, structure, closure, and avoidance of uncertainty (Jost et al. 2003; Jost, Federico, and Napier 2009). 
government intervention. In this respect, there is a strong link between legitimizing ideologies like racial resentment and policy attitudes.

Racial resentment is related to opposition to a range of race-conscious programs among white Americans, including welfare, affirmative action, and student financial aid (DeSante 2013; Sears and Henry 2003; Sidanius et al. 2000), but scholars are divided as to the precise nature of the connection between racial resentment and policy attitudes. Some argue that racial resentment derives from racial prejudice and that opposition to entitlement programs is based in thinly veiled antipathy toward blacks. ${ }^{6}$ From this perspective, racial resentment reflects the evolution of old-fashioned racism into a new form in response to changing social norms regarding the expression of overt prejudice (Kinder and Mendelberg 2000; Kinder and Sanders 1996). Alternatively, others argue racial resentment is more ideological - reflecting principled opposition to these programs based on a more general attitude toward self-reliance (Sniderman and Carmines 1997).

Feldman and Huddy (2005) argue the literature is unresolved on this point because racial resentment is more ideological among conservatives than liberals. In an experiment evaluating support for hypothetical scholarship programs, they found policy support among white liberals showed greater reactivity to racial cues than did support among white conservatives. Liberals high in racial resentment reported lower support for programs designed to benefit black students than for identical programs supporting white students. By contrast, racial resentment among conservatives was associated with program opposition regardless of the beneficiaries' race. This is not to say race does not matter for conservatives. Feldman and Huddy (2005) note that "while resentment has broad political effects among conservatives that transcend the specific racial targets of public policy and contradict the resentment-as-prejudice thesis, conservatives are not free of racial bias." Instead, race might be a chronically salient consideration for social policy in that it is inexorably intertwined with beliefs about individualism. Liberals, on the other hand, needed more of an explicit push to think of these policies in racial terms. When latent negative racial attitudes were activated, policy support decreased.

Feldman and Huddy's (2005) findings suggest it is important to consider the relationship between political ideology and system justification motives

6. While the name "racial resentment" seems to imply it is a general measure of racial attitudes, it stems from the back-white paradigm of race relations and focuses exclusively on attitudes toward African-Americans. We discuss this measure in greater detail on pp. 13-14. 
like racial resentment. Our study builds on this established perspective that ideology moderates the effect of racial attitudes on policy support. We extend this work by engaging intersectionality as a theoretical framework, investigating attitudes toward race-gender subgroups including Hispanic women (a group of women receiving scant attention in this regard) and evaluating the simultaneous effects of racial resentment and modern sexism on policy attitudes.

Modern sexism, like racial resentment, is characterized by an unwillingness to attribute gender inequality to discrimination and also to strong endorsement of traditional gender roles (Swim et al. 1995). It is similarly conceptualized as the evolution of overt sexism into a more subtle form. As is the case for racial resentment, modern sexism provides a rationale against government intervention into social problems by normalizing inequality between men and women (Jost et al. 2008). While related to political ideology (e.g., Conover 1988; Swim et al. 1995), the relationship between the two has not been explored in a fashion similar to racial resentment. Modern sexism and racial resentment share a similar underlying logic and, like all system-justifying ideologies, tend to covary (Jost and Hunyady 2005; Sidanius, Pratto, and Bobo 1994). ${ }^{7}$ In spite of their common origins and functions, research on racial attitudes and gender attitudes has developed relatively independently of each other. As a result, it remains unclear how these attitudinal processes interact to shape policy attitudes.

Intersectionality researchers are struggling with how to best integrate racism and sexism - both conceptually and methodologically. Dhamoon (2011) and Weldon (2006) argue for a highly contingent take on intersectional mechanisms; across given timeframes, contexts, groups, and individuals; attitudes about social groups are sometimes independent, sometimes additive, and sometimes multiplicative. While no single project or method can adequately address all of these complexities or alternatives, we argue that predispositions toward race and gender are activated by the way political issues are discussed in public discourse and that this activation shapes political attitudes differently based on the groups and subgroups that are made salient. Because there is an abundance of evidence that intersections between

7. While related to this "higher order" system justification factor, attitudes toward race and gender remain relatively distinct (e.g., Glick and Fiske 2001, 2011; Jackman 1994). Therefore, there is a need to look at discrete intergroup attitudes rather than simply a general orientation toward groupbased inequality. 
gender and race/ethnicity are politically relevant but no consensus on public opinion toward subgroups, there is a critical need to better understand the process by which gender issues become racialized and how this process contributes to the experience of "double-jeopardy" facing black and Hispanic women.

\section{HYPOTHESES}

To evaluate how legitimizing ideologies linked to race and gender collectively shape the structural disadvantage faced by black and Hispanic women, we conducted an experiment that varied racial and ethnic primes in a question about support for a gender-conscious policy - a fair-pay policy intended to eliminate wage discrimination facing women. By holding the policy constant but varying the salience of the different groups of women who would benefit from it, we can evaluate the intersection of attitudes toward race and gender. We hypothesize the following processes will govern reactions to the experiment and support for equal pay policy:

$\mathrm{H}_{1}$ : The inclusion of raciallethnic primes in a question about a genderconscious policy will activate racial resentment among white liberals and moderates, resulting in lower levels of policy support.

As noted above, prior research on racial resentment and political conservatism points to a complex relationship between the two. Notably, Feldman and Huddy (2005) illustrate that racial resentment conveys the effects of racial prejudice among white liberals but is more related to ideological principles than prejudice among white conservatives. We anticipate a similar pattern of results here, such that the activation of racial resentment and its impact on policy support is stronger among liberals than among conservatives; instead, conservatives will object to such policies regardless of the types of women cast as beneficiaries. Lower policy support among white liberals and moderates in the experimental conditions would point to the added impact of racial discrimrimination above and beyond gender discrimination - consistent with the concept of multiple jeopardy or intersectional disadvantage (Collins 2000; King 1988).

$\mathrm{H}_{2}$ : The inclusion of raciallethnic primes in a question about a genderconscious policy will not influence the effect of modern sexism on policy 
support. However, like racial resentment, modern sexism's effect will be moderated by political ideology.

We anticipate the effects of modern sexism will not vary across the experimental conditions because the gender content in them is held constant. This expectation is consistent with the idea of cumulative discrimination because we expect the effect of modern sexism on policy support to persist, rather than being dampened or swamped by racial resentment when the issue is racialized. We anticipate that the effect of modern sexism on policy support will be stronger among liberals than conservatives; conservatives will object to such policies regardless of their levels of modern sexism. While no studies have systematically explored how ideology conditions the relationship between modern sexism and policy attitudes, it seems logical to hypothesize that ideology moderates this relationship in the same way it moderates the relationship between racial resentment and policy attitudes. Both racial resentment and modern sexism tap similar underlying orientations towards group- based inequality as a social and political problem - namely individualism.

$\mathrm{H}_{3}$ : The relationship between modern sexism and policy support will be moderated by respondent gender.

While the two previous hypotheses are drawn from a structural persective on intersectionality, the more identity-based work in this area points toward a third hypothesis centered on respondent gender. Because the issue of equal pay disproportionately impacts the lives of women, female respondents may perceive gender discrimination to be more common than men do and thus score lower on modern sexism - a difference in levels (Swim et al. 1995). However, women may also rely more on perceptions of gender discrimination than male respondents in formulating their policy attitudes. This suggests a difference in not only levels, but also in effect sizes, such that it has a larger influence on women's policy attitudes.

\section{DATA AND METHOD}

To test these hypotheses, we utilized an experiment included in the 2012 Cooperative Congressional Election Study (CCES), as well as survey questions from the common content. ${ }^{8}$ The survey was administered by

8. The CCES is a survey administered to a stratified sample of more than 50,000 Americans. Half of the survey consists of common content questions, which are asked of all respondents. The other half of the survey consists of items developed by teams of researchers who purchased content modules. Each 
YouGov/Polimetrix in October 2012. The sample was drawn from the optin panel and adjusted to population characteristics using a two-stage sample matching technique (Vavreck and Rivers 2008). Our analysis is restricted to white Americans because racial minorities are underrepresented in the CCES sample relative to whites. As a result, we lack the statistical power necessary to evaluate experimental effects across racial groups. Also, the debate regarding whether racial resentment conveys veiled racial prejudice is specific to white Americans' racial attitudes (Feldman and Huddy 2005). Eliminating nonwhite respondents reduced the sample size from 739 to 551. Respondents' gender was well balanced with $51.5 \%$ female.

\section{THE EXPERIMENT}

Respondents were randomly assigned to one of three versions of a question pertaining to equal pay. The question stem and response options were consistent across each condition. The treatment conditions contained an additional statement about either black or Hispanic women that provided information about variation in the wage gap across groups. In this respect, we manipulate both the presence of the group cue and highlight the magnitude of the problem facing different groups of women. The precise question wordings in each condition are as follows:

Common Question Stem: "Pay equity means getting equal pay for equal work. In the U.S., women make an average of 78 cents for every dollar that men earn."

\begin{tabular}{ll}
\hline Condition & Modified Question Wording \\
\hline Control & No second sentence. \\
Black Women & But the wage gap is even larger for black women who make only \\
& 62 cents for every dollar earned by men. \\
Hispanic Women & $\begin{array}{c}\text { But the wage gap is even larger for Hispanic women who make } \\
\text { only } 52 \text { cents for every dollar earned by men. }\end{array}$ \\
\hline
\end{tabular}

content module was administered to a subset of the sample $(n=1000)$. Our experiment was part of this team content. The study was supported by the National Science Foundation (principle investigator, Stephen Ansolabehere). For more information, please visit http://projects.iq.harvard.edu/cces/home, or see Vavreck and Rivers (2008) for an in-depth treatment of the study's intellectual origins and sampling methodology. 
Common Question: "Some people feel the government should make sure women receive pay equity. Others feel that this is not the federal government's business. Place your view somewhere between the two alternatives."

\begin{tabular}{l|l|l}
\hline $\begin{array}{l}\text { It is not the government's } \\
\text { business. }\end{array}$ & 123456 & $\begin{array}{c}\text { The government should } \\
\text { make sure that women } \\
\text { receive pay equity. }\end{array}$ \\
\hline
\end{tabular}

Responses to this question were rescaled to range from 0 to 1 in subsequent analysis.

Because we are interested in attributions for group-based inequality, we employ measures of racial resentment and modern sexism. While the typical racial resentment scale contains four items, the CCES common content contained only two of the four:

“(1) Irish, Italian, Jewish, and many other minorities overcame prejudice and worked their way up. Blacks should do the same without any special favors, and (2) Generations of slavery and discrimination have created conditions that make it difficult for Blacks to work their way out of the lower class (reversed)."

Agreement with these statements was measured on a 5-point Likert scale, ranging from "strongly agree" to "strongly disagree." The items were rescaled to range from zero to one and combined to form a reliable scale $(\alpha=.77)$. High scores indicate respondents reject discrimination as a cause for racial inequality.

Racial resentment is measuring attitudes towards blacks only; it is not a direct measure of beliefs about Latinos' place in society. The measure stems from the black-white paradigm of race relations, and it is yet unclear how well attitudes toward Latinas fit into this framework. We have noted that beliefs about individualism underlie racial resentment such that inequality is attributed to factors like poor work ethic. Fox (2004) notes beliefs about work ethic are highly racialized for white Americans; an overwhelming majority feels whites' work ethic vastly exceeds that of both blacks and Hispanics. Because our experiment looks at opinion toward black women and Hispanic women, it is worth noting this limitation of our measure of racial attitudes. We do not contend that attitudes toward different racial and ethnic groups are interchangeable (Branton, Cassese, and Jones 2012) but instead rely on racial resentment to capture beliefs about group-based inequality, while recognizing that

9. See Kinder and Sanders (1996) for more information on this measure. 
this may be a cleaner measure for reactions to the "Black Women" condition compared to the "Hispanic Women" condition.

Two items measure modern sexism: "On average, women have lower incomes than men. How much of the economic difference between women and men: (1) Can be explained by discrimination in the work place (reversed)? (2) Occurs because society treats women less fairly than men (reversed)?" Responses were captured on a four-point Likert scale, ranging from "a great deal" to "not at all." The items were rescaled to range from zero to one and combined to form a modern sexism scale $(\alpha=.83) .{ }^{10}$ The construction of the modern sexism measure parallels racial resentment in that high scores correspond to rejection of the notion that gender inequality results from discrimination. Respondent gender (captured by a dummy variable) and ideology (a nominal measure indicating whether a respondent identified as a liberal, moderate, or conservative) are employed to test the conditional effects of the experimental treatment. Because random assignment to experimental conditions created essentially equivalent groups, sociodemographic control variables are excluded from the model. ${ }^{11}$

Descriptive statistics provide important information about the relationship between these key independent variables. Figure 1 plots the mean value of racial resentment and modern sexism by sex and ideology. The figure highlights that racial resentment and ideology are clearly connected, as a system justification perspective would suggest. Racial resentment increases monotonically between liberal, moderate, and conservative identifiers. A similar pattern is observed for modern sexism, although here, unlike for racial resentment, a significant gender difference is apparent. Women report lower levels of modern sexism than men across all ideological groups, meaning they are much more likely to attribute inequality to discrimination. These differences are striking, with conservative women reporting about the same level of modern sexism as liberal men. The relationships between these four factors will be important to bear in mind as we evaluate how each of them shapes support for fair-pay policies.

10. These items were placed before the experimental item on the survey instrument to ensure exogeneity.

11. Inclusion of controls for income, marital, and parental status did not appreciably change the results. 


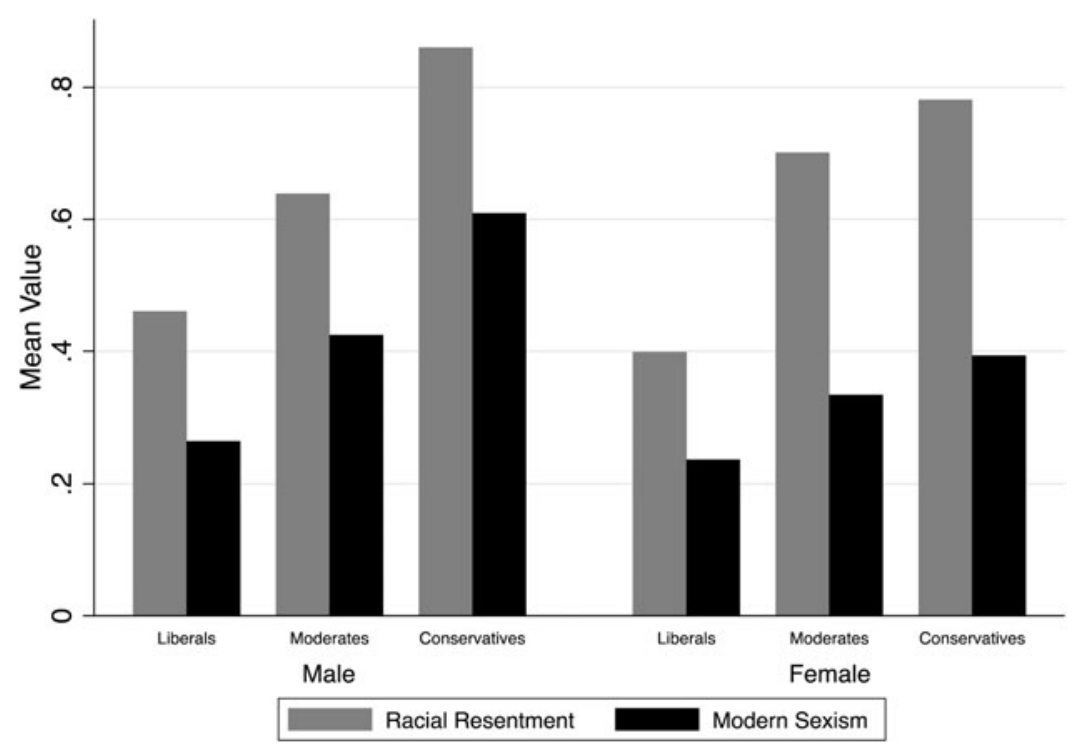

FiguRE 1. Mean values on racial resentment and modern sexism scales by gender and ideology. Source: 2012 Cooperative Congressional Election Study. Analysis includes white respondents only.

\section{RESULTS}

We begin by considering the average treatment effects for the experiment. Figure 2 graphs the average treatment effect - across ideology - on attitudes toward fair-pay policies. The figure indicates the racial cues had only very modest effects on support for pay equity. Instead, attitudes are driven largely by ideological principles. However, our expectations are more complex. The average treatment effects shown here do not reveal whether the effect of the manipulations is heterogeneous with respect to both ideology and racial resentment $\left(\mathrm{H}_{\mathrm{l}}\right)$. For instance, we expect liberals high and low on racial resentment should report markedly different levels of support in the experimental and control conditions. Thus, the key comparison is within ideological groups rather than simply across them.

We use a series of OLS regression models to tease out these moderating effects and evaluate support for $\mathrm{H}_{1}$. We include an interaction term between the experimental conditions and racial resentment to evaluate whether the experimental conditions activate racial resentment, thereby decreasing support for fair-pay policies. We estimate the models 


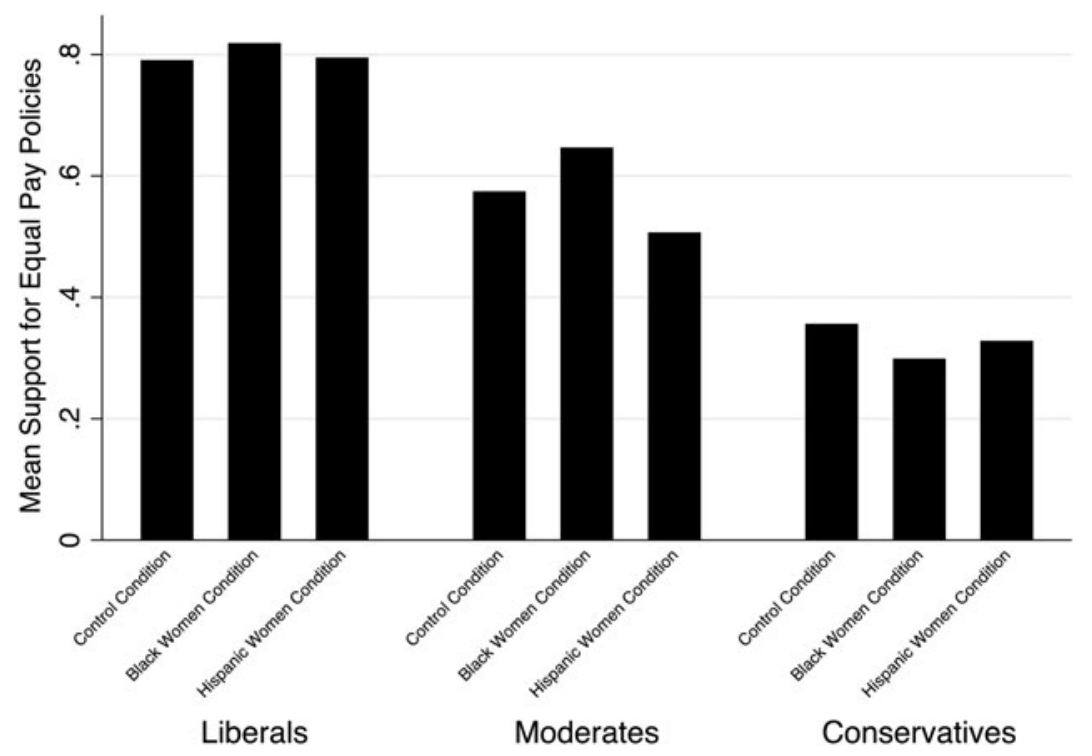

Figure 2. Average treatment effects by ideology. Source: 2012 Cooperative Congressional Election Study. Analysis includes white respondents only.

separately for each ideological group to determine whether racial resentment operates comparably across them. The results of this analysis are provided in Table 1.

The ideological groups diverge from each other in the manner we anticipated. Levels of support for pay-equity policy vary among liberals and moderates in the experimental conditions based on their level of racial resentment, while conservatives do not respond to the experiment. To illustrate the marginal effect of racial resentment on attitudes toward pay equity across ideological groups, we offer predicted values in Table 2. The table presents the expected value of policy support at the minimum and maximum value on the racial resentment measure for the two treatment groups and the control group.

Among both white liberals and moderates, the "Black Women" prime activates racial resentment and depresses policy support. Among liberals, as racial resentment increases from 0 to 1 , the predicted value for policy support decreases from .97 to $.55(\Delta=-.42)$. Among moderates, the predicted value decreases from .89 to $.51(\Delta=-.39)$ as racial resentment increases from 0 to 1 . The "Hispanic Women" prime significantly conditions the impact of racial resentment among liberals, 
Table 1. Treatment effects by racial resentment and ideology

\begin{tabular}{lcccc}
\hline & $\begin{array}{c}\text { Full } \\
\text { Sample }\end{array}$ & Liberals & Moderates & Conservatives \\
& & & \\
\hline Black Women condition & $0.10^{+}$ & 0.07 & $0.32^{* * *}$ & -0.17 \\
& $(.07)$ & $(0.06)$ & $(0.15)$ & $(0.27)$ \\
Hispanic Women condition & -0.01 & 0.01 & 0.13 & -0.08 \\
& $(0.08)$ & $(0.07)$ & $(0.19)$ & $(0.32)$ \\
Racial resentment & $-0.21^{* * *}$ & -0.12 & -0.04 & $-0.46^{*}$ \\
& $(0.09)$ & $(0.12)$ & $(0.15)$ & $(0.25)$ \\
Black Women & $-0.16^{+}$ & $-0.30^{+}$ & $-0.34^{+}$ & 0.14 \\
condition $\times$ racial resentment & $(0.11)$ & $(0.19)$ & $(0.22)$ & $(0.32)$ \\
Hispanic Women & -0.04 & -0.21 & -0.25 & 0.09 \\
condition $\times$ racial resentment & $(0.11)$ & $(0.20)$ & $(0.27)$ & $(0.37)$ \\
Female respondent & $0.08^{* * *}$ & -0.00 & $0.12^{* * *}$ & $0.09^{* *}$ \\
& $(0.03)$ & $(0.04)$ & $(0.06)$ & $(0.05)$ \\
Ideology & $-0.18^{* * *}$ & & & \\
Constant & $(0.02)$ & & & \\
& $1.04^{* * *}$ & $0.90^{* * *}$ & $0.52^{* * *}$ & $0.68^{* * *}$ \\
N & $(0.06)$ & $(0.06)$ & $(0.11)$ & $(0.21)$ \\
Adj. $R^{2}$ & 464 & 111 & 151 & 202 \\
\hline
\end{tabular}

Note: Analysis includes white respondents only. Standard errors are provided in parentheses. Significance tests are 1 -tailed t-tests. ${ }^{+} p<.10,{ }^{*} p<.05,{ }^{* * *} p<.01$.

but not moderates. Among liberals exposed to the "Hispanic Women" condition, support for pay equity decreases by .33 along the range of racial resentment. ${ }^{12}$

What might account for the discrepancy across conditions among moderates? One possibility is the specificity of the racial resentment measure to blacks. Attitudes towards blacks and Hispanics are typically correlated among whites due to their relationship to higher order constructs like ethnocentrism (Kinder and Kam 2009). But intergroup attitudes are not interchangeable - these are distinct racial and ethnic groups with different histories, experiences, and objective economic circumstances - as the wage differential between them suggests. However, racial resentment is serving as a rough proxy for racial attitudes toward Hispanics, and we must interpret these results with some caution.

12. In Table 1, the interaction term between the "Hispanic Women" condition and racial resentment does not appear significant among liberals. However, we were not able to evaluate significance based only on the regression coefficients for the interaction terms because the standard errors are conditional. For this reason, we tested the marginal effect of racial resentment in Table 2 and uncovered further support for $\mathrm{H}_{1}$ among liberals in the "Hispanic Women" condition. 
Table 2. Marginal effect of racial resentment across the treatment and control conditions

\begin{tabular}{|c|c|c|c|c|c|c|c|c|c|c|c|c|}
\hline & \multicolumn{3}{|c|}{ Full Sample } & \multicolumn{3}{|c|}{ Liberals } & \multicolumn{3}{|c|}{ Moderates } & \multicolumn{3}{|c|}{ Conservatives } \\
\hline & Min & $\operatorname{Max}$ & $\Delta$ & Min & $\operatorname{Max}$ & $\Delta$ & Min & $\operatorname{Max}$ & $\Delta$ & Min & $\operatorname{Max}$ & $\Delta$ \\
\hline Black Women condition & .78 & .41 & $-.37^{\text {**; }}$ & .97 & .55 & $-.42^{* *}$ & .89 & .51 & $-.39^{* * *}$ & .56 & .24 & -.32 \\
\hline Hispanic Women condition & .67 & .41 & $-.26^{\text {策 }}$ & .91 & .59 & $-.33^{*}$ & .71 & .42 & -.29 & .65 & .28 & -.36 \\
\hline Control condition & .68 & .47 & $-.21 *$ & .90 & .78 & -.12 & .58 & .53 & -.04 & .71 & .26 & $-.46 *$ \\
\hline
\end{tabular}

Note: Analysis includes white respondents only. Significance tests are 1-tailed t-tests. ${ }^{+} p<.10,{ }^{*} p<.05,{ }^{* *} p<.01$. 
Despite this limitation, our experiment reveals some evidence of the "double jeopardy" facing black and Hispanic women: policy support is lower when these groups of women are mentioned as beneficiaries, in spite of their greater need for protections in the economic sphere. Racial resentment underlies this reduction in policy support among white liberals and moderates. Among these groups, there is no difference in support based on respondents' levels of racial resentment in the control condition - ostensibly because it is not activated in the absence of racial/ethnic cues. Among white conservatives, the effect of racial resentment on policy support does not vary across conditions at all, suggesting that the presence of racial cues does not activate this predisposition and bring it to bear on policy attitudes. These results demonstrate the ways in which ideology modifies the effects of racial resentment on policy support. The results lend additional evidence for the idea that racial resentment conveys the effects of racial prejudice among liberals and moderates but is more related to ideological principles than prejudice among conservatives (Feldman and Huddy 2005).

Next, we extend our models to evaluate whether the relationship between modern sexism and policy support is moderated by political ideology $\left(\mathrm{H}_{2}\right)$ and respondent gender $\left(\mathrm{H}_{3}\right)$. The results are presented in Table 3. We find the effect of modern sexism on male opinion toward pay equity is negative, significant, and fairly consistent in size across ideological groups. Among women, however, the effect is more variable and thus more clearly moderated by ideology. These findings are consistent with $\mathrm{H}_{2}$ and $\mathrm{H}_{3}$ and effectively bridge the two hypotheses by showing that the relationship between modern sexism and policy support is conditioned simultaneously by both gender and ideology.

To further illustrate the joint effect of ideology, modern sexism, and respondent gender on attitudes toward pay equality, we again offer predicted values of policy support in Table 4 . The bottom half of the table presents the expected value at the minimum and maximum value on the modern sexism measure for men and women in the full sample and in each of the ideological groups. These predicted values highlight the varying effects of modern sexism among women. For liberal women, support declines as one moves from the minimum to maximum value of modern sexism $(\Delta=.14)$, but the change is not statistically significant. Support is high regardless of beliefs about the origins of gender-based inequality. Among female moderates, support significantly declines from .77 to $.50(\Delta=-.17)$. This effect is only slightly smaller than for 
Table 3. Conditional effects of gender resentment on policy support

\begin{tabular}{lcccc}
\hline & Full & Liberals & Moderates & Conservatives \\
& Sample & & & \\
\hline Black Women condition & 0.05 & 0.04 & $0.27^{*}$ & $-0.29^{+}$ \\
& $(0.06)$ & $(0.06)$ & $(0.14)$ & $(0.22)$ \\
Hispanic Women condition & -0.01 & 0.03 & 0.12 & -0.07 \\
& $(0.07)$ & $(0.06)$ & $(0.18)$ & $(0.26)$ \\
Racial resentment & $-0.17^{* * *}$ & -0.07 & -0.06 & $-0.34^{*}$ \\
& $(0.08)$ & $(0.14)$ & $(0.13)$ & $(0.20)$ \\
Black Women & -0.09 & $-0.24+$ & $-0.28^{+}$ & 0.28 \\
condition $\times$ racial resentment & $(0.10)$ & $(0.19)$ & $(0.21)$ & $(0.26)$ \\
Hispanic Women & -0.03 & $-0.30^{+}$ & -0.17 & 0.07 \\
condition $\times$ racial resentment & $(0.10)$ & $(0.20)$ & $(0.26)$ & $(0.29)$ \\
Modern sexism & $-0.39^{* * *}$ & $-0.45^{* * *}$ & $-0.38^{* * *}$ & $-0.35^{* * *}$ \\
& $(0.07)$ & $(0.12)$ & $(0.15)$ & $(0.12)$ \\
Female respondent & $0.06^{+}$ & -0.06 & 0.10 & $0.14^{+}$ \\
& $(0.04)$ & $(0.06)$ & $(0.11)$ & $(0.10)$ \\
Female respondent $\times$ modern & -0.07 & $0.24^{+}$ & -0.02 & $-0.30^{* * *}$ \\
sexism & $(0.09)$ & $(0.18)$ & $(0.22)$ & $(0.15)$ \\
Ideology & $-0.14^{* * *}$ & & & \\
& $(0.02)$ & & & \\
Constant & $1.10^{* * *}$ & $0.99^{* * *}$ & $0.67^{* * *}$ & $0.80^{* * *}$ \\
$N$ & $(0.06)$ & $(0.06)$ & $(0.11)$ & $(0.17)$ \\
Adj. $R^{2}$ & 463 & 111 & 151 & 201 \\
\hline & 0.39 & 0.21 & 0.12 & 0.22 \\
\hline
\end{tabular}

Notes: Analysis includes white respondents only. Standard errors are provided in parentheses.

Significance tests are 1 -tailed t-tests. ${ }^{+} p<.10,{ }^{*} p<.05,{ }^{* * *} p<.01$.

moderate men, suggesting modern sexism operates similarly among moderates regardless of sex. The effect of modern sexism on policy support is most pronounced for conservative women $(\Delta=-.44)$, and this effect is nearly double that observed for conservative men $(\Delta=-.23)$. Thus, ideology and beliefs about gender-based inequality emerge as important sources of heterogeneity among women's political thinking.

The inclusion of modern sexism does not appreciably alter the results of the experiment with respect to the activation of racial resentment and subsequent reduction in policy support. The results regarding the impact of racial resentment are substantively and statistically consistent with the results in Tables 1 and 2 when modern sexism is included in the model. The point estimates in the top half of Table 4 support our previous conclusions about the conditioning effects of ideology. For white liberals, exposure to the black and Hispanic women experimental 
Table 4. Marginal effect of racial resentment and modern sexism by sex of respondent

\begin{tabular}{|c|c|c|c|c|c|c|c|c|c|c|c|c|}
\hline \multicolumn{13}{|c|}{ Racial Resentment } \\
\hline & \multicolumn{3}{|c|}{ Full Sample } & \multicolumn{3}{|c|}{ Liberals } & \multicolumn{3}{|c|}{ Moderates } & \multicolumn{3}{|c|}{ Conservatives } \\
\hline & Min & $\operatorname{Max}$ & $\Delta$ & Min & $\operatorname{Max}$ & $\Delta$ & Min & Max & $\Delta$ & Min & $\operatorname{Max}$ & $\Delta$ \\
\hline Black Women condition & .70 & .44 & -.27 \% & .93 & .62 & $-.31 *$ & .85 & .51 & $-.34 *$ & .34 & .29 & -.06 \\
\hline Hispanic Women condition & .64 & .44 & $-.20 *$ & .92 & .55 & $-.37^{*}$ & .71 & .46 & -.23 & .55 & .29 & -.27 \\
\hline Control condition & .65 & .48 & $-.17 *$ & .89 & .82 & -.07 & .57 & .51 & -.06 & .63 & .29 & $-.34 *$ \\
\hline \multicolumn{13}{|c|}{ Modern Sexism } \\
\hline & \multicolumn{3}{|c|}{ Full Sample } & \multicolumn{3}{|c|}{ Liberals } & \multicolumn{3}{|c|}{ Moderates } & \multicolumn{3}{|c|}{ Conservatives } \\
\hline & Min & $\operatorname{Max}$ & $\Delta$ & Min & $\operatorname{Max}$ & $\Delta$ & Min & Max & $\Delta$ & Min & $\operatorname{Max}$ & $\Delta$ \\
\hline Female respondent & .72 & .26 & $-.46^{* * *}$ & .86 & .72 & -.14 & .77 & .50 & 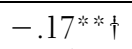 & .64 & .20 & 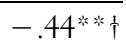 \\
\hline Male respondent & .66 & .27 & $-.39 * *$ & .92 & .62 & $-.30 * \frac{*}{\dagger}$ & .67 & .42 & $-.25^{* * 1}$ & .49 & .26 & $-.23 *$ \\
\hline
\end{tabular}

Analysis includes white respondents only. Significance tests are l-tailed t-tests. ${ }^{+} p<.10,{ }^{*} p<.05,{ }^{* * *} p<.01$. $\nmid$ The expected values in these cells are based on setting modern sexism to .66 to estimate its effect at its maximum value. There were too few cases to present the estimate for the maximum value of modern sexism (at 1 ) due to the limited number of cases at the extreme for this ideological subset of respondents. 
conditions decreases support for the policy among those with heightened levels of racial resentment. The same is true for moderates, but only in the "Black Women" condition. The results again indicate exposure to the race conditions has no significant impact among conservatives. In sum, after controlling for modern sexism, the effect of racial resentment persists, and the effect is conditioned on one's ideological leaning. Further, there is no evidence that racial attitudes replace or wash out the effect of attitudes toward gender when race is made salient. Instead, attitudes toward race and gender jointly shape policy support when race is made salient by the experiment-consistent with the notion that attitudes toward race and gender collaborate to shape political opinion.

\section{DISCUSSION}

This study affords insight into the social forces that contribute to persistent intracategorical disparities among women. Policies ensuring pay equity stand to disproportionality benefit black and Hispanic women, who face larger wage gaps and higher rates of poverty. However, our experiment showed that the greater economic disparities experienced by black and Hispanic women did not correspond to greater policy support among many white Americans. Instead, mentions of the greater wage gap facing black women reduced policy support among liberals and moderates high in racial resentment. Mentions of Hispanic women similarly reduced support among white liberals. Among conservatives, opinion was not similarly racialized because it was characterized by uniformly low levels of policy support.

Evidence that resentment is more clearly racial for liberals than conservatives should not obscure the fact that overall policy support is higher among liberals than conservatives. While ideology is a primary determinant of policy attitudes, racial resentment and modern sexism further condition ideological differences. Collectively, our results suggest racial attitudes, rather than the objective need faced by these groups of women, are central determinants of policy support among many Americans. These results are consistent with public opinion research on similar policies. For instance, affirmative action policies enjoy more public support when white women are featured as the primary beneficiaries, and, in practice, these policies have contributed to greater gains for white women relative to black and Hispanic women (Bobo and Kluegel 1993; Sidanius et al. 2000; Strolovitch 1998). Our results clearly 
demonstrate that marginalized subgroups of women live at the crossroads of multiple forms of disadvantage and are subject to a variety of "disempowering dynamics" that contribute to and perpetuate stratification.

Our racial resentment and political ideology findings are consistent with prior work demonstrating that ideology moderates the effect of racial attitudes on policy support (Feldman and Huddy 2005). We built on this work by engaging intersectionality as a theoretical framework, experimentally manipulating the salience of race-gender subgroups and evaluating the simultaneous effects of racial resentment and modern sexism on policy support. We found that the relationship between modern sexism and policy support, like that between racial resentment and policy support, is quite complex. While both racial resentment and modern sexism captured similar attributions for group-based economic inequality, they interacted with political ideology to shape opinion in different ways. Though both serve a kind of system justification function, they are not interchangeable. Gender relations are characterized by significantly more intimacy than race relations (Jackman 1994) and, as a result, tend to reflect more ambivalent attitudes and stereotypes (Glicke and Fiske 2001, 2011). Therefore, scholars should consider discrete intergroup attitudes rather than simply a general orientation toward economic inequality or individualism absent specific mentions of social groups.

Unpacking the relationship between modern sexism and political attitudes was further complicated by respondent gender. It is not surprising that some women endorse modern sexism or that it influences their policy attitudes. Past research shows that minority group members sometimes endorse system justification beliefs that disadvantage their own group (Jost and Hunyady 2005). However, a sense of gender identity or commonality with other members of their marginalized group (sometimes referred to as "intersectionally linked fate") seems to mitigate against this tendency (Dawson 2012; Strolovitch 2007). In order to better understand the gender differences observed here, future research should look more closely at how gender and feminist identity relates to the legitimizing ideologies explored here.

The degree of complexity involved in our study of intersectional bias speaks to ongoing conceptual and methodological debates within the field of intersectionality research (Dhamoon 2011; Hancock 2007b; Weldon 2006). In particular, this work grapples with the question of whether intersectionality involves additive, multiplicative, or convergent processes. Our methodological approach relies on both additive and 
multiplicative conceptualizations of intersectional bias. The effects of racial resentment and modern sexism on policy attitudes are additive in the sense that they are captured by a linear regression model. The coefficient on racial resentment is added to the coefficient for modern sexism (among the coefficients on the other variables in the model) when calculating predicted policy support. The process is also multiplicative in the sense that (1) the experiment activates resentment differently among different groups based on their stable levels of racial resentment and ideological leanings and (2) the relationship between ideology, modern sexism, and policy attitudes is moderated by respondent gender.

However, the structure of our analysis was driven in large part by our experimental design, which focused on the activation of latent racial attitudes across conditions. It shows that racial resentment is sometimes activated by the experiment and that the effect of modern sexism continues to influence policy support - it is not replaced or attenuated by the activation of racial attitudes. We used a multiplicative term to show this activation process. Because our analysis is specific to our experiment, our findings do not settle larger questions about the independent, additive, or multiplicative processes characterizing intersectional bias. Multiple aspects of categorical thinking like racial resentment and modern sexism are not necessarily relevant for political attitudes in fixed ways (Dhamoon 2011), and our work supports the idea that identities and systems of oppression do not operate in a static or straightforward fashion.

This fluid aspect of intersectionality motivated our experimental approach. Experimentation is increasingly used to study racial attitudes (e.g., Banks and Valentino 2012; DeSante 2013; Huddy and Feldman 2009), but much of this work has yet to directly engage the intersectionality literature and its insights into multiple, simultaneous disempowering dynamics. (For a notable exception, see McConnaughy and White 2014.) One of the primary benefits of an experimental approach is that it maximizes internal validity by allowing us to cleanly manipulate the presence of racial cues in the survey question. As a result, we are able to make "situated comparisons" about the process of racialization and gendering in this particular policy context (Dhamoon 2011, 236).

The tradeoff is more limited external validity. However, given that arguments about fair-pay policies are often couched in different frames, our experiment provides some insight into the immediate impact of framing on policy support. Collectively, our results point toward a 
disempowering dynamic facing black and Hispanic women in the United States. In this respect, our study compliments other theoretical work on intersectionality, particularly scholarship grounded in standpoint epistemology, which delves directly into the concrete personal experiences of these subgroups of women (Collins 2000; Naples 1999). While we cannot speak directly to other policy domains, our results and theoretical development suggest that gender is effectively racialized in other policy domains and that our findings reflect the broader social processes characterizing this disempowering dynamic.

Feminist theory motivated our research question and experimental design, and we hope it illustrates that the epistemological divide between theoretical and positivist work is not insurmountable. Debate persists on how to best conduct intersectionality research, and our work does not settle this debate. We expect that greater cross-pollination and dialogue between feminist theorists and feminist empiricists can advance feminist scholarship in a broad sense by allowing for triangulation on the political implications of intersectionality. Ultimately, our results complement the intersectionality literature it draws on by demonstrating that both racial resentment and modern sexism jointly shape public policies designed to improve the economic circumstances of women. The results are consistent with the economic stratification observed between white, black, and Hispanic women (IWPR 2013) and also with accounts of "double jeopardy" and cumulative discrimination (e.g., Purdie-Vaughns and Eibach 2008).

Erin C. Cassese is an Associate Professor of Political Science at West Virginia University, Morgantown, WV: Erin.Cassese@mail.wvu.edu; Tiffany D. Barnes is an Assistant Professor of Political Science at the University of Kentucky, Lexington, KY: tiffanydbarnes@uky.edu; Regina P. Branton is an Associate Professor of Political Science at the University of North Texas, Denton, TX: branton@unt.edu.

\section{REFERENCES}

Banks, Antoine J., and Nicholas A. Valentino. 2012. "Emotional Substrates of White Racial Attitudes.” American Journal of Political Science 56 (2): 286-97.

Bobo, Lawrence, and James Kluegel. 1993. "Opposition to Race Targeting: Self Interest, Stratification Ideology, or Racial Attitudes?” American Sociological Review 58 (4): 443-64.

Branton, Regina, Erin Cassese, and Bradford Jones. 2012. "Race, Ethnicity, and U.S. House Incumbent Evaluations.” Legislative Studies Quarterly 37 (4): 465-89.

Cole, Elizabeth R. 2009. "Intersectionality and Research in Psychology." American Psychologist 64 (3): 170-80. 
Cole, Elizabeth R., and Abigail Stewart 2001. "Invidious Comparisons: Imagining a Psychology of Race and Gender Beyond Differences.” Political Psychology 22 (2): $293-308$.

Collins, Patricia Hill. 2000. Black Feminist Thought: Knowledge, Consciousness, and the Politics of Empowerment. New York: Routledge.

Conover, Pamela Johnston. 1988. "Feminists and the Gender Gap." Journal of Politics 50 (4): 985-1010.

Crenshaw, Kimberle Williams. 1991. "Mapping the Margins: Intersectionality, Identity Politics, and Violence Against Women of Color." Stanford Law Review 43 (6): 1241 -99.

—_ 1993. "Demarginalizing the Intersection of Race and Sex: A Black Feminist Critique of Antidiscrimination Doctrine, Feminist Theory and Antiracist Politics." In Feminist Legal Theory, ed. D. Kelly Weisburg. Philadelphia: Temple University Press, 383-95.

Dawson, Michael C. 2012. Blacks In and Out of the Left: Past, Present and Future. Chicago: University of Chicago Press.

DeSante, Christopher D. 2013. "Working Twice as Hard to Get Half as Far: Race, Work Ethic, and America's Deserving Poor." American Journal of Political Science 57 (2): $342-56$

Dhamoon, Rita Kaur. 2011. “Considerations on Mainstreaming Intersectionality.” Political Research Quarterly 64 (1): 230-43.

Feldman, Stanley, and Leonie Huddy. 2005. "Racial Resentment and White Opposition to Race-Conscious Programs: Principles or Prejudice?” American Journal of Political Science 49 (1): 168-83.

Fox, Cybelle. 2004. “The Changing Color of Welfare? How Whites' Attitudes toward Latinos Influence Support for Welfare." American Journal of Sociology 110 (3): 580-625.

Glicke, Peter, and Susan Fiske. 2001. "An Ambivalent Alliance: Hostile and Benevolent Sexism as Justifications for Gender Inequality.” American Psychologist 56 (2): 109-18.

- 2011. "An Ambivalent Sexism Revisited." Psychology of Women Quarterly 35 (3): $530-35$.

Hancock, Ange-Marie. 2007a. "Intersectionality as Normative and Empirical Paradigm." PS: Political Science \& Politics 37 (1): 41-45.

—. 2007b. "When Multiplication Doesn't Equal Quick Addition: Examining Intersectionality as a Research Paradigm." Perspectives on Politics 5 (1): 63-79.

Harris-Perry, Melissa V. 2011. Sister Citizen: Shame, Stereotypes, and Black Women in America. New Haven, CT: Yale University Press.

Huddy, Leonie, Erin Cassese, and Mary-Kate Lizotte. 2008. "Gender, Public Opinion, and Political Reasoning." In Political Women and American Democracy, ed. Christina Wolbrecht, Karen Beckwith, and Lisa Baldez. Cambridge: Cambridge University Press, 31-49.

Huddy, Leonie, and Stanley Feldman. 2009. "On Assessing the Political Effects of Racial Prejudice." Annual Review of Political Science 12 (1): 423-47.

Institute for Women's Policy Research (IWPR). 2013. “The Gender Wage Gap: 2012.” http:// www.iwpr.org/publications/pubs/the-gender-wage-gap-2012 (accessed March 15, 2013).

Jackman, Mary. 1994. The Velvet Glove: Paternalism and Conflict in Gender, Class and Race Relations. Berkeley: University of California Press.

Jost, John T., and Mahzarin Banaji. 1994. "The Role of Stereotyping in System-Justification and the Production of False Consciousness." British Journal of Social Psychology 33 (1): $1-27$.

Jost, John T., Chistopher M. Federico, and Jamie L. Napier. 2009. "Political Ideology: Its Structure, Functions, and Elective Affinities.” Annual Review of Psychology 60 (1): 309-37.

Jost, John T., Jack Glaser, Arie W. Kruglanski, and Frank J. Sulloway. 2003. "Political Conservatism as Motivated Social Cognition." Psychological Bulletin 129 (3): 339-75. 
Jost, John T., and Orsolya Hunyady. 2005. "Antecedents and Consequences of SystemJustifying Ideologies." Current Directions in Psychological Science 14 (5): 260-65.

Jost, John T., Cheryl J. Wakslak, and Tom R. Tyler. 2008. "System Justification Theory and the Alleviation of Emotional Distress." Advances in Group Processes 25: 181-211.

Kinder, Donald R., and Cindy D. Kam. 2009. Us Against Them: Ethnocentric Foundations of American Opinion. Chicago: The University of Chicago Press.

Kinder, Donald R., and Tali Mendelberg. 2000. "Individualism Reconsidered: Principles and Prejudice in Contemporary American Opinion." Racialized Politics: The Debate about Racism in America, ed. David O. Sears, Jim Sidanius, and Lawrence Bobo. Chicago: University of Chicago Press, 44-74.

Kinder, Donald R., and Lynn M. Sanders. 1996. Divided by Color: Racial Politics and Democratic Ideals. Chicago: University of Chicago Press.

King, Deborah K. 1988. "Multiple Jeopardy, Multiple Consciousness: The Context of a Black Feminist Ideology.” Signs 14 (1): $42-72$.

Kirkness, Verna. 1988. "Emerging Native Women." Canadian Journal of Women and Law $2(2): 408-15$.

Levin, Shana, Stacey Sinclair, Rosemary Veniegas, and Pamela Taylor. 2002. "Perceived Discrimination in the Context of Multiple Group Membership." Psychological Science 13 (6): 557-60.

McConnaughy, Corrine M., and Ismail K. White. 2014. "Racial Politics Complicated: The Work of Gendered Race Cues in American Politics." Working paper, George Washington University.

Naples, Nancy A. 1999. “Towards Comparative Analyses of Women's Political Praxis: Explicating Multiple Dimensions of Standpoint Epistemology for Feminist Ethnography." Women \& Politics 20 (1): 29-57.

Purdie-Vaughns, Valerie, and Richard Eibach. 2008. "Intersectional Invisibility: The Distinctive Advantages and Disadvantages of Multiple Subordinate-Group Identities." Sex Roles 59: 377-91.

Roberts, Dorothy. 1999. Killing the Black Body. New York: Vintage Books.

Sears, David O., and Patrick J. Henry. 2003. “The Origins of Symbolic Racism.” Journal of Personality and Social Psychology 85 (2): 259-75.

Sidanius, Jim, Shana Levin, James Liu, and Felicia Pratto. 2000. "Social Dominance Orientation, Antiegalitarianism, and the Political Psychology of Gender: An Extension and Cross-cultural Replication." European Journal of Social Psychology 30 (1): $41-67$.

Sidanius, Jim, and Felicia Pratto. 1993. "Racism and Support of Free-Market Capitalism: A Cross-Cultural Analysis." Political Psychology 14 (3): 381-401.

1999. Social Dominance: An Intergroup Theory of Social Hierarchy and Oppression. New York: Cambridge University Press.

Sidanius, Jim, Felicia Pratto, and Lawrence Bobo. 1994. "Social Dominance Orientation and the Political Psychology of Gender." Journal of Personality and Social Psychology 67 (6): $998-1011$.

Sidanius, Jim, and Rosemary C. Veniegas. 2000. "Gender and Race Discrimination: The Interactive Nature of Disadvantage." In Reducing Prejudice and Discrimination, ed. Stuart Oskamp. Mahwah, NJ: Lawrence Erlbaum Associates, 47-69.

Simien, Evelyn. 2007. "Doing Intersectionality Research: From Conceptual Issues to Practical Examples." Politics \& Gender 3 (2): 36-43.

Simien, Evelyn M., and Ange-Marie Hancock. 2011. "Mini-Symposium: Intersectionality Research." Political Research Quarterly 64 (1): 185-86.

Sniderman, Paul M., and Edward Carmines. 1997. Reaching Beyond Race. Cambridge: Harvard University Press. 
Strolovitch, Dara Z. 1998. "Playing Favorites: Public Attitudes toward Race- and Gender Targeted Anti-discrimination Policy.” National Women's Studies Association Journal 10 (3): $27-53$.

- 2007. Affirmative Advocacy: Race, Class and Gender in Interest Group Politics. Chicago: University of Chicago Press.

Swim, Janet K., Kathryn J. Aikin, Wayne S. Hall, and Barbara A. Hunter. 1995. "Sexism and Racism: Old-Fashioned and Modern Prejudices." Journal of Personality and Social Psychology 68 (2): 199-214.

Vavreck, Lynn, and Douglas Rivers. 2008. "The 2006 Cooperative Congressional Election Study." Journal of Elections, Public Opinion and Parties 18 (4): 355-66.

Weldon, Laurel. 2006. "The Structure of Intersectionality: A Comparative Politics of Gender." Politics ङ Gender 2 (2): 235-48. 